\title{
Albumin-based Nanoconjugates for Targeted Delivery of Therapeutic Oligonucleotides
}

\author{
Xin Ming ${ }^{*}$, Kyle Carver, and Lin Wu ${ }^{\dagger}$ \\ Division of Molecular Pharmaceutics, UNC Eshelman School of Pharmacy, University of North \\ Carolina, Chapel Hill, NC 27599, USA
}

\begin{abstract}
Nanoparticle-based delivery has become an important strategy to advance siRNA and antisense oligonucleotides into clinical reality. However, limited biodistribution of nanoparticles and the toxicity of some nanocarriers restrict the wider application of this strategy. To address these issues we aimed to construct oligonucleotide delivery systems which are non-cytotoxic and smaller than typical nanoparticles. Thus, a morpholino oligonucleotide was conjugated to a tumor-targeting RGD peptide, and then, multiple RGD-oligo conjugates were linked to a single molecule of human serum albumin via a reductively responsive linkage. The resultant nanoconjugates showed uniform and monodispersed size distribution with a diameter of $13 \mathrm{~nm}$. A single nanoconjugate molecule contains 15 oligonucleotides as well as 15 targeting ligands on the surface of albumin. The nanoparticle demonstrated 61-fold enhancement in receptor-specific cellular delivery of oligonucleotides in integrin-expressing tumor cells compared to the non-targeted control nanoconjugates and were able to robustly enhance functional activity of the oligonucleotide at low nanomolar concentrations without causing cytotoxicity. Due to their small size, the targeted nanoconjugates could penetrate deeply and distribute throughout 3-D tumor spheroids, whereas the conventional nanoparticles with sizes over $300 \mathrm{~nm}$ could only deliver to the cells on the surface of the tumor spheroids. As a result of their greater cellular delivery, smaller size, and lack of cytotoxicity compared to conventional nanoparticles, the multivalent nanoconjugates may provide an effective tool for targeting oligonucleotides to tumors and other diseased tissues.
\end{abstract}

\section{Keywords}

Targeted delivery; Therapeutic Oligonucleotides; Albumin; Conjugation

\section{INTRODUCTION}

Antisense and siRNA oligonucleotides promise to become a new generation of anti-tumor agents, as they enjoy high specificity by recognizing their targets based on base pairing, and are capable of manipulating many desirable targets that are "undruggable" by small molecules.[1] New types of therapeutic oligonucleotides, such as microRNA antagonists and splice-switching oligonucleotides (SSOs), provide additional tools to modulate the

(C) 2013 Elsevier Ltd. All rights reserved.

*Corresponding author: Dr. Xin Ming, Division of Molecular Pharmaceutics, UNC Eshelman School of Pharmacy, 1073 Genetic Medicine Building, University of North Carolina, Chapel Hill, NC 27599, USA. Tel: 919-966-4343. xming @email.unc.edu.

$\dagger^{\dagger}$ urrent address: Clinical Research Center, The First Affiliated Hospital of Nanjing Medical University, Nanjing 210029, China

Publisher's Disclaimer: This is a PDF file of an unedited manuscript that has been accepted for publication. As a service to our customers we are providing this early version of the manuscript. The manuscript will undergo copyediting, typesetting, and review of the resulting proof before it is published in its final citable form. Please note that during the production process errors may be discovered which could affect the content, and all legal disclaimers that apply to the journal pertain. 
expression and function of tumor related genes.[2-4] For example, SSOs can modulate alternative splicing by hybridizing to pre-mRNA sequences and blocking access of various splicing factors.[2] Thus, an SSO can redirect Bcl-x splicing from anti-apoptotic $\mathrm{Bcl}-\mathrm{x}_{\mathrm{L}}$ to pro-apoptotic Bcl- $\mathrm{x}_{\mathrm{S}}$ and thereby induce apoptosis of cancer cells.[5] By eliminating an over-expressed cancer-permissive splice variant and inducing an apoptotic splice variant simultaneously, SSOs can potentially achieve greater pharmacological effect than small molecule inhibitors that only act on a single function. $[2,6]$ Despite their enormous potential, pharmacological targets within the cells are poorly accessible to oligonucleotides since they are hydrophilic and often charged macromolecules.[7] Utilization of nanoparticles as delivery vehicle holds promise for unleashing the tremendous potential of therapeutic oligonucleotides for tumor therapy. Yet, for ultimate translation of oligonucleotides into clinical reality, the current delivery systems need to be optimized to confront the challenges posed by the highly heterogeneous and dynamic nature of tumors.[8]

The size of nanoparticles must be optimized in order for them to overcome the delivery barriers in vivo, as particle size has a substantial impact on the biodistribution of nanoparticles, especially to tumor sites.[9] Particles larger than $7 \mathrm{~nm}$ (the size of albumin) typically have low renal filtration; however, those larger than $300 \mathrm{~nm}$ tend to be cleared quickly by the reticuloendothelial system.[10] Thus, nanoparticles with a size between 7 and $300 \mathrm{~nm}$ can remain in the circulation for a long time, which is a prerequisite for targeted tumor delivery. On the other hand, larger particles may take advantage of the enhanced permeability and retention (EPR) effect in tumor sites.[11] From studies with xenograft tumor models in mice, nanoparticles with a size around $400 \mathrm{~nm}$ tend to maximally exploit the EPR effect.[12] However, the validity of this rule for drug delivery to human tumors is controversial since xenograft tumor models are fundamentally different from spontaneous human tumors.[13] Tumors are highly heterogeneous in terms of vascular leakage.[14] Larger particles may have better distribution in leaky sites of tumors; however, poor delivery to less leaky sites will lead to incomplete eradication of the tumor, resulting in tumor relapse. Further, most solid tumors develop high interstitial fluid pressure which reduces convection of the nanoparticles from the circulation to tumor tissues.[15, 16] Thus, nanoparticle delivery to tumors, largely through diffusion, favors smaller particles.[14] Taken together, we consider smaller nanoparticles $(7-50 \mathrm{~nm})$ a superior system for delivering oligonucleotides to tumors.

Targeted delivery is another way to overcome the biological barriers limiting oligonucleotide-based therapeutics.[7] To achieve active targeting, a ligand on the delivery system binds to its receptor on the surface of diseased cells and then undergoes receptormediated endocytosis, so as to overcome the cell membrane barrier for intracellular delivery of oligonucleotides.[17] In addition, the therapeutic significance of tumor targeting lies in the ability to accumulate a drug specifically to cancer cells and thereby to enhance therapeutic activity and minimize drug-related toxicity. To achieve tumor targeting in vivo, multivalent display of the targeting moiety is often required to achieve effective binding to the target cells in a physiological environment, where the endogenous ligands compete for binding to the target and the shear stress in the circulation drag the delivery system away from the tumor site.[18] For example, polymer-based nanoparticles coated with multiple transferrin ligands were able to deliver siRNAs to solid tumors overexpressing transferrin receptors and cause gene specific $R N A i$ activity in humans;[19] this clinical study highlights the advantage of using nanoparticles to construct multivalent targeting systems.

Taken together, ideal tumor targeting nanoparticles should be versatile enough to display multivalent targeting ligands and carry sufficient payload. Yet, equally important is that they are small enough to penetrate all tumor tissues with diverse vascular leakage. It is a tremendous challenge to construct versatile but small nanoparticles for oligonucleotide 
delivery. Currently, nanoparticles of oligonucleotides are often prepared by complexation of cationic lipids and polymers with negatively charged oligonucleotides. This method often leads to heterogeneous and polydisperse structures that are typically larger than $100 \mathrm{~nm}$. Thus, the resultant nanoparticles have not successfully translated oligonucleotide-based therapy into clinical reality due to disadvantages such as incomplete delivery, low reproducibility, and considerable systemic toxicity[20]. In this study, we aim to use chemical conjugation methods to construct polycationic-free nanoparticles that combine broad biodistribution and multivalent tumor targeting for oligonucleotide delivery.

\section{Materials and Methods}

\section{Preparation of Albumin-based Nanoconjugates}

The overall strategy was to covalently conjugate SSOs to the RGD peptide that was selective for integrin av $\beta 3$, a cell surface glycoprotein that is preferentially expressed in angiogenic endothelia and in some tumors,[21] and then link multiple RGD-SSO conjugates to a molecule of albumin as a carrier protein. The SSO (5'-

GTTATTCTTTAGAATGGTGC-3') was custom synthesized by Gene Tools, LLC (Philomath, OR, USA). This oligonucleotide was phosphorodiamidate morpholino oligomer (PMO) functionalized with a primary amine at the 5 position and a disulfide amide for sulfhydryl linkage at the $3^{\prime}$ position, and was referred to as $\mathrm{NH}_{2}$-PMO-S-S-R. RGD peptide was conjugated to the amine group at the $5^{\prime}$ end of the PMO according to a method described previously.[22] Briefly, a maleimide group was introduced to the PMO by reacting it with $N$-[ץ-maleimidobutyryloxy] succinimide ester (GMBS, Thermo Fisher Scientific, Rockford, IL, USA) at a 3:1 molar ratio of GMBS to PMO in phosphate buffered saline (PBS, pH 7.2) for $30 \mathrm{~min}$ at room temperature, and this was followed by gel filtration in an illustra NAP-25 Column (GE Healthcare, Uppsala, Sweden). The thiol group on cyclic RGDfK needed for conjugation was freshly generated by incubation of cyclo[RGDfK(Ac-SCH $\left.\mathrm{H}_{2} \mathrm{CO}\right)$ ] (Peptide International, Louisville, KY, USA) in the Deacetylation Solution (50 mM Hydroxylamine, $5 \mathrm{mM}$ EDTA in PBS, $\mathrm{pH}$ 7.0) at room temperature for $1 \mathrm{~h}$. The maleimide group on the PMO was then reacted with the thiol group of cyclic RGDfK at a 1:3 molar ratio of maleimide to thiol in PBS with 5 mM EDTA ( $\mathrm{pH} \mathrm{7.0)}$ ) for $1 \mathrm{~h}$ at room temperature, and the resultant peptide-PMO conjugates were purified by gel filtration in an illustra NAP-25 Column (GE Healthcare).

Human serum albumin (HSA) was labeled with a fluorescent dye at Cys-34 by reacting it with Alexa Fluor ${ }^{\circledR} 633 \mathrm{C}_{5}$ Maleimide (Life Technologies, Carlsbad, CA, USA) at a 1:3 molar ratio of protein to dye in PBS supplemented with $1 \mathrm{mM}$ EDTA (pH 7.0) for $2 \mathrm{~h}$ at room temperature. The labeled HSA was purified by gel filtration in a PD-10 Desalting Column (GE Healthcare). The amino groups of the albumin were then reacted with the bifunctional crosslinker $N$-succinimidyl 3-(2-pyridyldithio) propionate (SPDP, Thermo Fisher Scientific) at a 1:25 molar ratio of protein to linker in PBS with 1 mM EDTA (pH 7.5) for $1 \mathrm{~h}$ at room temperature. The excess amount of SPDP was removed by gel filtration in a PD-10 Column. The average number of 2-pyridyldithio group (the sulfhydryl-reactive portion of SPDP) linked to albumin was determined as 18 by observing the release of pyridine-2-thione $\left(\lambda_{\max }=343 \mathrm{~nm}\right)$ from the intermediate HSA-SPDP conjugates after being treated with excess amount of DTT (Sigma-Aldrich, St. Louis, MO, USA).

The thiol group on the RGD-PMO conjugates needed for conjugation with the 2pyridyldithio group on albumin was freshly generated by treating the disulfide bond of the RGD-PMO-S-S-R conjugates with $10 \mathrm{mM}$ DTT for $1 \mathrm{~h}$ at room temperature, and any residual amount of DTT was removed by gel filtration in an illustra NAP-25 Column. The 2pyridyldithio groups on the albumin derivative were then reacted with the thiol group of RGD-PMO conjugates at a 1:20 molar ratio of protein to conjugate in PBS with $1 \mathrm{mM}$ 
EDTA ( $\mathrm{pH}$ 7.0) overnight at room temperature, and the final product was purified by gel filtration using a column with Sephadex G-100 gel (GE Healthcare) to remove the excess amount of the RGD-PMO conjugates and other byproducts.

In order to prepare control nanoconjugates without the RGD peptides, the PMO with the same sequence but only functionalized with disulfide amide at the 3 ' position was custom synthesized by Gene Tools, LLC. After treatment with DTT, the PMO with a thiol group was reacted with the SPDP modified albumin in the same conditions as that for preparation of the RGD targeted nanoconjugates.

\section{Physical Characterization of Nanoconjugates}

The final products were first analyzed using size-exclusion chromatography. Samples (100 $\mu \mathrm{L}$ ) containing the nanoconjugates or albumin were injected into a Varian HPLC system (ProStar/Dynamax, Walnut Creek, CA, USA) equipped with a Yarra SEC-3000 column (Phenomenex, Torrance, CA, USA). The nanoconjugates containing PMOs were detected by OD260, while the albumin was detected by OD280. Gel Filtration Markers Kit for Protein Molecular Weights 29,000-700,000 Da (Sigma) was used as the size standards.

The average particle sizes of the nanoconjugates in PBS were determined using a Zetasizer Nano (Malvern Instruments, Westborough, MA, USA) at a fixed angle of $90^{\circ}$ and a temperature of $25^{\circ} \mathrm{C}$. Light scattering intensity was maintained within the required range of the instrument $\left(5 \times 10^{4}\right.$ to $1 \times 10^{6}$ counts/sec $)$ in all the measurements. Each sample was analyzed in triplicate.

The size of the nanoconjugates was confirmed with Transmission Electron Microscopy (TEM). In this experiment, the targeted nanoconjugates were diluted and dropped on 200 mesh carbon-coated copper grids (Ted Pella, Redding CA) and allowed to attach for $2 \mathrm{~min}$. Uranyl acetate aqueous solution (4\%) was then added on the grid for 2 min to counterstain the nanoparticles. Samples were viewed using a LEO EM910 transmission electron microscope operating at $80 \mathrm{kV}$ (LEO Electron Microscopy, Oberkochen, Germany). Digital images were acquired using a Gatan Orius SC1000 CCD Digital Camera and Digital Micrograph 3.11.0 (Gatan, Pleasanton, CA, USA).

\section{Serum Stability and Release of PMO by Sulfhydryls}

The HSA-(PMO-RGD) 15 nanoconjugates containing $1 \mu \mathrm{M}$ PMO were incubated in PBS containing $20 \%$ serum at $37{ }^{\circ} \mathrm{C}$ for $16 \mathrm{~h}$ or in PBS containing $10 \mathrm{mM}$ glutathione and 100 $\mu \mathrm{M}$ cysteine at at $37^{\circ} \mathrm{C}$ for $4 \mathrm{~h}$, using PBS as a control. After incubation, samples were eluted in a column with Sephadex G-100 gel. The PMO contents in the fractions were then detected by OD260, while the albumin was detected by Alexa Fluor 633 fluorescence.

\section{Cells}

Integrin av $\beta 3$ expressing A375SM cells were stably transfected with a reporter gene comprised of the firefly luciferase coding sequence interrupted by an aberrant intron, as described previously,[23] and were referred to as A375/Luc705 cells. They were cultured in DMEM medium (Life Technologies, Grand Island, NY, USA) containing 10\% FBS (Sigma) and $200 \mu \mathrm{g} / \mathrm{mL}$ hygromycin B (Roche, Mannheim, Germany). M $21^{+}$melanoma cells with

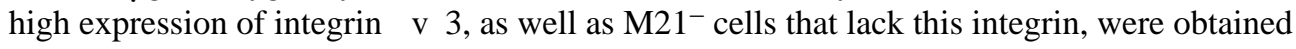
from Dr. D. Cheresh (University of California, San Diego, CA, USA)[24] and were cultured in DMEM medium supplemented with 10\% FBS. 


\section{Cellular uptake}

Total cellular uptake of the Alexa Fluorß 633-labeled nanoconjugates was measured by flow cytometry using a LSR II cell analyzer (Becton-Dickenson, San Jose, CA, USA). After treatment with the nanoconjugates for $4 \mathrm{~h}$, the cells were trypsinized and were analyzed by flow cytometry, with a $639 \mathrm{~nm}$ laser coupled with a 675/20 emission filter for Alexa Fluor ${ }^{\circledR}$ 633.

\section{Oligonucleotide Treatment of Cells and Luciferase Assay}

A375/Luc705 cells were seeded on 24-well plates at $5 \times 10^{4}$ cells per well. On the following day, the nanoconjugates in $500 \mu \mathrm{l}$ of Opti-MEM I medium (Life Technologies) were then added to each well. Following the 4-h treatment at $37^{\circ} \mathrm{C}$, FBS was added to each well to the concentration of $1 \%(\mathrm{v} / \mathrm{v})$. After $16 \mathrm{~h}$, cells were washed with PBS and incubated in DMEM supplemented with $1 \%$ FBS for $48 \mathrm{~h}$ prior to harvest. Activation of luciferase gene expression due to correction of splicing by the SSO was determined using a Luciferase assay kit (Promega, Madison, WI, USA) on a FLUOstar Omega microplate reader (BMG LABTECH, Cary, NC, USA). Protein content was determined by the BCA protein assay (Thermo Fisher Scientific) with bovine serum albumin as a standard. Background luciferase expression was determined by measuring luciferase activity in the cells without the oligonucleotide treatment, and these values were then subtracted from the results in the treated cells to obtain response values to represent the increase of luciferase expression by the nanoconjugates of the SSO.

\section{Confocal Fluorescence Microscopy}

Live cell confocal microscopy was performed to examine the subcellular distribution of the targeted nanoconjugates. The A375/Luc705 cells were transfected with baculovirus expression vectors for GFP chimeras of Rab5, Rab7, or lysosome-associated membrane glycoprotein 1 (LAMP-1) (Organelle Lights ${ }^{\mathrm{TM}}$, Life Technologies). The day following transfection cells were incubated with the Alexa Fluor ${ }^{\circledR}$ 633-labeled nanoconjugates (50 nM equivalent PMOs) in Opti-MEM media for $4 \mathrm{~h}$. Cells were imaged on a Zeiss 510 meta confocal microscope using $488 \mathrm{~nm}$ and $633 \mathrm{~nm}$ laser lines.

\section{Tumor Spheroid Study}

Tumor spheroids were grown using A375/GFP cells to study nanoconjugate uptake and penetration in three-dimensional (3-D) culture according to a method described previously. [25] Briefly, two thousand of the cells in $30 \mu \mathrm{L}$ of cell suspension were seeded to each well of a sterilized Nunc Microwell ${ }^{\mathrm{TM}}$ MiniTrays (Fisher Scientific, Pittsburgh, PA, USA). The tray was then inverted and placed on an orbital shaker in $\mathrm{CO}_{2}$ incubator and left undisturbed for 7 days; at this point the spheroids were approximately $400 \mu \mathrm{m}$ in diameter. After washing with PBS, the spheroids were placed in a 1.5\% agarose-coated 48 well plate with $200 \mu \mathrm{L}$ OptiMEM media and were treated with nanoparticles for $4 \mathrm{~h}$. Spheroids were harvested and fixed in 4\% paraformaldehyde before being mounted on a slide with fluoromount G (Electron Microscopy Sciences, Hatfield, PA, USA). Images were taken on a Zeiss 510 meta confocal microscope.

\section{Cytotoxicity Assay}

The cytotoxicity of nanoconjugates was measured with the Alamar Blue assay. In brief, A375/Luc705 cells were seeded in 96-well plates at 3000 cells/well. After 24 hours, the cells were exposed to different concentrations of nanoconjugates for $24 \mathrm{~h}$. Dose-containing medium was replaced with fresh medium, and cells were incubated for another $48 \mathrm{~h}$. Alamar Blue reagent (Life Technologies) was added and incubated for 2 hour. The samples were 
read in a FLUOstar Omega microplate reader (BMG LABTECH, Cary, NC, USA) set at 540 $\mathrm{nm}$ excitation wavelength and $590 \mathrm{~nm}$ emission wavelength.

\section{Data Analysis}

Data are expressed as mean \pm SD from three measurements unless otherwise noted. Statistical significance was evaluated using $t$-test for two-sample comparison or ANOVA followed by Dunnet's test for multiple comparisons. The data were analyzed with GraphPad Prism 5 (GraphPad Software, Inc., La Jolla, CA, USA).

\section{RESULTS}

\section{Synthesis and Characterization of Nanoconjugates}

The overall strategy for preparation of the nanoconjugates is outlined in Fig 1. First, the single sulfhydryl group on HSA was labeled with the far red fluorophore Alexa Fluor® 633. Subsequently, approximately 18 surface amino groups were reacted with the bifunctional reagent SPDP, which was determined by release of the colored product pyridine-2-thione $\left(\lambda_{\max }=343 \mathrm{~nm}\right)$ from the modified albumin by DTT treatment. After introducing a maleimide group to the $5^{\prime}$-end of PMO using a bi-functional linker GMBS, excess thiolcontaining cyclic RGD peptide was reacted with the terminal maleimide groups to form RGD-PMO conjugates. After generation of free thiol groups at the $3^{\prime}$-end of PMOs, they were linked to the SPDP-conjugated albumin to form RGD nanoconjugates. To prepare control nanoconjugates without RGD ligands, PMOs containing only a disulfide bond at 3'end were treated with DTT and were then reacted with the SPDP modified albumin. The number of PMOs linked to the albumin was determined in two ways. First, formation of the colored product pyridine-2-thione was monitored as the 3 -thiol PMO reacted with the SPDP-conjugated albumin. Second, the concentrations of PMO and HSA in the purified final product were determined using OD260 and Alexa Fluor® 633 fluorescence, respectively, and then were used to calculate the ratio of PMO to HSA in the final product. Both of these methods led to close agreement with 15-16 oligonucleotides linked per albumin in various preparations. The targeted and control nanoconjugates were then termed HSA-(PMO-RGD) 15 and HSA-PMO ${ }_{15}$, respectively.

The SEC-HPLC behaviors of the starting materials and the final nanoconjugates are illustrated in Fig 2A. Alexa Fluor ${ }^{\circledR}$ 633-modified HSA eluted earlier than the RGD-PMO direct conjugates in the column with the retention time of 8.6 and 10.9 min, respectively. When the RGD-PMO conjugates were further linked to the albumin, the final nanoconjugates eluted even earlier than the albumin itself with the retention time of $7.8 \mathrm{~min}$. The minor peak in front of the HSA chromatography peak represents aggregates of albumin proteins. Correspondingly, there was a small front peak in the chromatography for the targeted nanoconjugates, which may result from conjugation of the RGD-PMO conjugates to the albumin aggregates. Thus, the final products of the nanoconjugates are as homogenous as albumin and linking multiple RGD-PMO does not cause aggregation of albumin.

The molecular size of the resultant nanoconjugates was estimated using dynamic light scattering and transmission electron microscopy. Average particle sizes for the starting material albumin and the nanoconjugates measured by dynamic light scattering are summarized in Table 1 and a representative size distribution graph is shown in Fig S1. The diameters for albumin, the control, and targeted nanoconjugates were 7.14, 12.74, and 12.95 $\mathrm{nm}$, respectively. There was no statistical difference between the sizes of the targeted and control nanoconjugates. Polydispersity index values were small (about 0.3 ), indicating uniform and monodispersed nanoparticles. The targeted nanoconjugates were visualized by 
TEM which revealed a diameter averaging $10 \mathrm{~nm}$, consistent with their hydrodynamic size (Fig 2B). The nanoconjugates are stable for at least 3 months when stored in buffer at room temperature, with no indication of aggregation or loss of biological activity.

\section{Serum Stability and Release of PMO by Sulfhydryls}

We first tested the serum stability of the targeted nanoconjugates by incubation in PBS or PBS with $20 \%$ serum at $37^{\circ} \mathrm{C}$ for up to $16 \mathrm{~h}$. The incubated samples were eluted in a column with Sephadex G-100 gel, which separates the nanoconjugates and albumin from the RGD-PMO conjugates. For both PBS and serum treated samples, the PMO contents (measured by OD260) overlapped the albumin contents (measured by Alexa Fluor ${ }^{\circledR} 633$ fluorescence) (Fig 3), indicating the RGD-PMO conjugates were not cleaved by PBS or serum treatment and the targeted nanoconjugates were stable in serum for at least $16 \mathrm{~h}$. Then, we tested whether intracellular sulfhydryls can release the PMOs from the nanoconjugates using PBS containing $10 \mathrm{mM}_{\mathrm{L}}$-glutathione and $100 \mu \mathrm{M}$ cysteine, the typical free thiol concentrations in the cytosol.[26] In gel filtration of the treated sample using a Sephadex G-100 column, over 78\% of PMO contents eluted slower and were separated from the nanoconjugates or albumin contents when incubated in the sulfhydryl solution for $4 \mathrm{~h}$ (Fig 3), indicating that the majority of the RGD-PMO conjugates were released from the nanoconjugates by the sulfhydryls. We tested cellular uptake of the treated samples in A375/ Luc705 cells. Consistent with the gel filtration result, the targeted nanoconjugates after PBS or serum treatment maintained their receptor-selective uptake, whereas cellular uptake of the sample treated by the sulfhydryls was dramatically reduced (Fig S2), suggesting that the RGD-PMO conjugates was released from the Alexa Fluor® 633 labeled albumin by sulfhydryls.

\section{Cellular Uptake of Nanoconjugates}

The total cellular uptake of targeted and control nanoconjugates was evaluated by incubating cells with these molecules for $4 \mathrm{~h}$ and then measuring total cell-associated fluorescence by flow cytometry. As seen in Fig 4A, there was 61-fold greater uptake of the targeted nanoconjugate as compared to the control nanoconjugates. Co-incubation with excess amounts $(10 \mu \mathrm{M})$ of a cyclic RGD peptide (RGDfV), a selective inhibitor of integrin $\alpha v \beta 3$, led to inhibition of the uptake of the targeted nanoconjugates, but did not affect that of the control nanoconjugates. Moreover, uptake of the targeted nanoconjugates was 18 -fold higher in integrin av 33 -expressing $\mathrm{M} 21^{+}$cells than that in $\mathrm{M}^{2} 1^{-}$cells that lack this integrin (Fig 4B). These observations support the concept that the cellular uptake of the RGD nanoconjugates depends on the integrin av $\beta 3$ receptor-mediated endocytosis. Cell uptake of the nanoconjugates was evaluated as a function of concentration. The uptake of the HSA$(\mathrm{PMO}-\mathrm{RGD})_{15}$ nanoconjugates as a function of concentration was well described by a classic saturable michaelis-menten model, whereas that for the control conjugates showed linear uptake (Fig 4C). These data are consistent with a saturable, receptor-mediated endocytosis accounting for uptake of the targeted nanoconjugate in A375/Luc705 cells.

By controlling the ratio of the SDPD modified albumin and RGD-PMO-SH conjugates in the final conjugation reaction, we prepared nanoconjugates that contain 5 or 10 RGD-PMO conjugates per albumin molecule, and they were termed as HSA-(PMO-RGD) 5 and HSA(PMO-RGD) 10 . The same amounts of the three nanoconjugates ( $3.3 \mathrm{nM}$ of albumin) were dosed to A375/Luc705 cells and total cellular uptake of the nanoconjugates was measured by flow cytometry. As shown in Fig 4D, the uptake was proportional to the number of RGD ligands displayed on the surface of the nanoconjugates. The uptake for the HSA-(PMORGD) ${ }_{15}$ nanoconjugates were 3- and 1.6-folded higher than that for HSA-(PMO-RGD) 5 and HSA-(PMO-RGD) 10 , respectively. 


\section{Intracellular Trafficking of Nanoconjugates}

We examined the subcellular distribution of the nanoconjugates. As seen in Fig 5A, live cells treated with the targeted nanoconjugates displayed substantial intracellular fluorescence at $4 \mathrm{~h}$, where cells treated with the control nanoconjugates exhibited little intracellular fluorescence. To further understand the cellular uptake and trafficking of the targeted nanoconjugates, we utilized chimeras of GFP with marker proteins for specific endomembrane compartments to visualize the subcellular distribution of the targeted nanoconjugates in live cells. As seen in Fig 5B, there was considerable co-localization of the fluorescent nanoconjugates with Rab7 and LAMP-1, markers for late endosome and lysosome, respectively, indicating that the RGD targeted nanoconjugates were transported to late endosomes and lysosomes. In contrast, at this point in the uptake process, there was little co-localization of fluorescent nanoconjugate with Rab5, the early endosome marker.

\section{Functional Activity of Nanoconjugates}

In order to evaluate the pharmacological effectiveness of the conjugates, A375/Luc705 cells were incubated with PMOs, the RGD-PMO conjugates, the control HSA-PMO 15 nanoconjugates, and targeted HSA-(PMO-RGD) 15 nanoconjugates, all containing $50 \mathrm{nM}$ PMOs, and the increase in luciferase activity was quantitated using the luciferase activity assay. As indicated in Fig 6A, treatment with the HSA-(PMO-RGD) 15 nanoconjugates produced a significant increase in luciferase expression compared to PMO (14.1-fold), the RGD-PMO conjugates (11.0-fold), and the control nanoconjugates (16.2-fold) at the same concentration. As shown Fig 6B, co-incubation with $10 \mu \mathrm{M}$ RGDfV peptide led to full inhibition of the effect of the HSA-(PMO-RGD) 15 nanoconjugates on luciferase induction. In contrast, RGDfV did not affect the luciferase induction by the control HSA-PMO 15 nanoconjugates. This observation supports the concept that the effect of the targeted nanoconjugates on splicing largely depends on its initial uptake via integrin av $\beta 3$. As shown in Fig 6C, the luciferase induction by the targeted nanoconjugates as a function of concentration was also saturable and well described by a general sigmoid model. These data suggests that saturable, receptor-mediated endocytosis is the main contributor to the effectiveness of the targeted nanoconjugates.

To further enhance functional delivery of SSOs by the targeted nanoconjugates, we applied a small molecule called Retro-1 that promotes release of oligonucleotides from late endosomes,[27] where the targeted nanoconjugates traffic (Fig 5B). After treating the A375/ Luc705 cells with targeted nanoconjugates, we further treated them with Retro1 at different doses. Dramatic enhancement of luciferase induction was observed with increasing doses of Retro-1 and the induction level with $50 \mu \mathrm{M}$ Retro-1 treatment was superior to the Lipofectamine formulation of phosphorothioate (PS) SSO in the same sequence and at the same concentration (Fig 6D).

\section{Uptake of Nanoconjugates in Tumor Spheroids}

We investigated tumor penetration of the targeted nanoconjugates using tumor spheroids of A375/GFP cells. For comparison, we included two conventional nanoparticles for oligonucleotide delivery prepared by complexation methods, Lipofectamine 2000 complexes of negatively charged PS SSO and PEI polyplexes of RGD-PS oligo conjugates. They have particle sizes of 870 and $336 \mathrm{~nm}$, respectively, and showed potent cellular delivery into the tumor cells in 2-D culture.[28, 29] There was no obvious difference in morphology of the spheroids after $4 \mathrm{~h}$ treatment with the targeted nanoconjugates and the two control nanoparticles, as compared to untreated control spheroids. Confocal imaging was carried out in order to visualize the site of localization of the nanoparticles in the spheroid. As shown in Fig 7, the lipoplexes and polyplexes could only deliver oligonucleotides to the cells on the surface of spheroids. In contrast, the targeted nanoconjugates were homogeneously 
distributed throughout the spheroid, within the observable depth of the confocal microscope $(\sim 75 \mu \mathrm{m})$, suggesting that small nanoparticles can penetrate deeply into the spheroid. To confirm the superior penetration of the nanoconjugates in tumor spheroid, we digested the tumor spheroids into single cells and measured cellular uptake of the nanoparticles using flow cytometry. As shown in Fig S3, the cells from the spheroids treated with the targeted nanoconjugates showed a homogenous increase in cellular uptake, while the cells from spheroids treated with the lipoplexes or polyplexes showed less than $10 \%$ of cells with increased cellular uptake, confirming the result obtained from confocal microscopy.

\section{Toxicity}

There was little toxicity associated with the use of the nanoconjugates at the concentrations examined. Thus in the Alamar Blue assay, the viability of the cells treated with up to 800 $\mathrm{nM}$ equivalent oligonucleotides in nanoconjugates were over $90 \%$ of the control cells (Fig 8). In the dose-response and time-response studies, the cells treated by the nanoconjugates showed similar total protein amounts as compared to the untreated control cells in BCA assay (data not shown). In addition, the cells treated with the nanoconjugates maintained normal morphology as illustrated in the confocal images of Fig 5.

\section{Discussion}

To overcome the various inherited disadvantages of conventional delivery systems for therapeutic oligonucleotides, we aimed to construct monomolecular nanoconjugates that are small, highly specific, and non-cytotoxic. Thus, albumin, neutral morpholino oligomers, and RGD peptides are selected as the carrier, therapeutic entity, and targeting moiety, respectively, because all of them have demonstrated superior safety profiles in clinical applications. Further, we utilize the morpholino oligomers as not only cargo molecules but also building blocks to display targeting ligands on nanoparticles, and thereby we are able to prepare nanoparticles that are $13 \mathrm{~nm}$ in diameter but versatile in displaying multivalent targeting ligands and carrying high payloads.

The resultant nanoconjugates showed uniform and monodispersed size distribution with a diameter of $13 \mathrm{~nm}$, and thus they are large enough to avoid quick renal filtration but small enough to penetrate through the vasculatures in tumor sites. These smaller nanoconjugates are especially advantageous over conventional nanoparticles (typically larger than $100 \mathrm{~nm}$ ) due to their ability to deliver to less leaky tumor sites, where relatively tight vasculatures and high interstitial fluid pressure prevent effective tumor penetration by the larger nanoparticles. Recently, polyplexes of $6 \mathrm{~nm}$ hydrodynamic diameter has been constructed for siRNA delivery.[30] However, only one molecule of siRNA duplex was loaded in this delivery system.[30] In contrast, a single molecule of our nanoconjugates contains 15 oligonucleotides. Thus the loading efficiency of oligonucleotides was estimated to be over $60 \%$, which provides another advantage over the conventional nanoparticles prepared by complexation.

Ideally, oligonucleotide delivery systems should be stable in blood so that they can circulate long enough to allow targeted delivery in tumor sites. On the other hand, to produce pharmacological actions, the therapeutic oligonucleotides must release from the delivery system in the target cells so that they can cross nuclear membrane and bind their target premRNA in the nucleus.[7, 31] We utilized a reductively responsive linkage disulfide bond to link PMOs to albumin so that cellular glutathione can potentially break the linkage and release the PMOs in the target cells. The stability study using cell-free assays revealed that the targeted nanoconjugates are stable in serum while the majority of the oligonucleotides can be released from the nanoconjugates by glutathione at the intracellular level. When the nanoconjugates are delivered into the cells, intracellular glutathione could potentially break 
the disulfide bond and release the PMOs. The kinetics of PMO release in the cells will be examined by using more sensitive assay to quantify cellular PMO level in future studies.

The nanoparticle demonstrated 61-fold enhancement in receptor-specific uptake of oligonucleotides in tumor cells compared to the non-targeted control nanoconjugates. This dramatically increased uptake is due to display of multivalent targeting ligands on the surface of the nanoconjugates as the uptake level was proportional to the number of RGD ligands displayed on the surface of the nanoconjugates (Fig 4D). In addition, the targeted nanoconjugates produced 11-fold higher functional activity of SSO compared to the monomeric RGD-PMO conjugates when the same amount of PMOs were used (Fig 6A). These observations support the notion that displaying multivalent targeting peptides on the surface of a nanoparticle can dramatically enhance binding affinity of the ligands to the receptors.[32] Further, these data indicate that the enhanced receptor binding can lead to superior receptor-mediated cellular uptake and functional delivery of oligonucleotides. Initial uptake of the nanoconjugates is followed by sequential intracellular trafficking into a variety of endomembrane compartments. In this study, we observed that the RGD-targeted nanoconjugates were partially transported to late endosomes and lysosomes, but not to early endosomes (Fig 5B). In addition, functional delivery of the targeted nanoconjugates was dramatically increased by Retro-1 (Fig 6D), which has been shown to promote the release of oligonucleotides from late endosomes.[27] Thus, these results support the notion that the targeted nanoconjugates escape from late endosomes in the cells. Because the fluorescent dye was linked to albumin instead of PMO, it is still unknown where the PMOs are released from the albumin carrier. Thus, additional studies are warranted to reveal precise trafficking pathways of the nanoconjugates.

The targeted nanoconjugates can robustly enhance functional activity of the oligonucleotide at low nanomolar concentrations, indicating that the enhancement in cellular uptake by multivalent targeting leads to an increase in pharmacological activity of the oligonucleotides. A PMO, capable of inducing exon skipping in dystrophin pre-mRNA in the nucleus, has shown to restore dystrophin function in patients with Duchenne muscular dystrophy in a phase II clinical trial.[33] However, without using any delivery system, a high dosage (> $2 \mathrm{mg} / \mathrm{kg}$ bodyweight) of this PMO was required to demonstrate its functional activity in the patients.[33] Consistent with this clinical observation, over $1 \mu \mathrm{M}$ PMO was needed to induce reporter gene expression in a cellular model.[34] In this study, the targeted nanoconjugates produced a 14-fold higher induction than free PMO at the same PMO concentration, indicating that the targeted nanoconjugates may produce therapeutic effects at a lower dose.

For complete eradication of solid tumors, anticancer drugs, including therapeutic oligonucleotides, must penetrate tumors efficiently and reach all cancer cells in a therapeutic concentration.[35] Tumor spheroids resemble micrometastasis or intervascular regions of large solid tumors and have an in vivo-like differentiation pattern due to cell-matrix and cell-cell interactions, and therefore have been used to study tumor penetration of anticancer drugs. [25, 36] It has been reported recently that tumor penetration and cellular uptake of ultrasmall gold nanoparticles were similar in tumor spheroids and tumor xenograft in mice, indicating tumor spheroid is a good model to examine nanoparticle penetration behavior. [37] In this study, the targeted nanoconjugates could penetrate deeply and distribute throughout 3-D tumor spheroids, whereas the conventional nanoparticles with sizes over 300 $\mathrm{nm}$ could only deliver to the cells on the surface of the tumor spheroids (Fig 7). This result supports the notion that smaller nanoparticles show superior penetration behavior into tumor spheroids than larger nanoparticles.[38] However, there are more biological barriers preventing drug delivery to tumor in vivo compared to tumor spheroid model. For example, interstitial fluid pressure of solid tumors is higher than that in tumors spheroids due to lack 
of blood vessels in spheroids. Therefore, further development of the nanoconjugate delivery system will entail substantial in vivo experimentation.

In spite of substantial uptake of the targeted nanoconjugates in the cells, little cytotoxicity was observed with the use of the nanoconjugates in various experiments in this study. As substantial toxicity was observed in application of cationic delivery systems for therapeutic oligonucleotides [20], we avoided using cationic carriers in this delivery system. Instead, albumin was selected because of its long history as a biodegradable and nontoxic carrier for drug delivery.[39] In addition, the PMOs are neutral oligonucleotides and have been well tolerated with no drug-related side effects when given to patients with Duchenne muscular dystrophy [33]. Utilization of targeted delivery can lower the oligonucleotide dose that is required for desired pharmacological outcomes, and thus can further reduce the possibility of toxicity caused by the therapeutic oligonucleotides.

\section{CONCLUSIONS}

In the current study, we successfully prepared monomolecular nanoconjugates that are small, highly specific, and non-cytotoxic. The resultant nanoconjugates with a diameter of $13 \mathrm{~nm}$ may have improved half-life in circulation and a broader tissue distribution profile compared to conventional nanoparticles for oligonucleotide delivery. In spite of their small size, the loading efficiency (over 60\%) of our nanoconjugates is greater than many nanoparticles currently used for drug/gene delivery. By utilizing oligonucleotides as not only cargo molecules but also building blocks for the display of targeting ligands on nanoparticles, we are able to prepare nanoparticles that are $13 \mathrm{~nm}$ in diameter but versatile in displaying multivalent targeting ligands and carrying high payloads. Thus, the targeted nanoconjugates demonstrated dramatic increases in receptor-specific cellular uptake, tumor penetration, and functional activity of therapeutic oligonucleotides in cancer cells. Due to the superior cellular delivery and smaller size compared to typical nanoparticles, multivalent nanoconjugates may provide an effective tool for targeting oligonucleotides to tumors and other diseased tissues.

\section{Supplementary Material}

Refer to Web version on PubMed Central for supplementary material.

\section{Acknowledgments}

The authors gratefully acknowledge Dr. Rudy L. Juliano (University of North Carolina, Chapel Hill, NC, USA) for invaluable discussion on the study and proof-reading of the manuscript; Dr. M. Joseph Costello (University of North Carolina, Chapel Hill, NC, USA) for TEM processing; Dr. David Cheresh (University of California, San Diego) for providing M21 $1^{+}$and M21- melanoma cells. This work was supported by NIH grants 5U54CA151652, UL1RR025747 and 5R01CA151964.

\section{REFERENCES}

[1]. Juliano R, Alam MR, Dixit V, Kang H. Mechanisms and strategies for effective delivery of antisense and siRNA oligonucleotides. Nucleic Acids Res. 2008; 36:4158-71. [PubMed: 18558618]

[2]. Kole R, Krainer AR, Altman S. RNA therapeutics: beyond RNA interference and antisense oligonucleotides. Nat Rev Drug Discov. 2012; 11:125-40. [PubMed: 22262036]

[3]. Bauman JA, Kole R. Modulation of RNA splicing as a potential treatment for cancer. Bioeng Bugs. 2011; 2:125-8. [PubMed: 21637003]

[4]. Garzon R, Marcucci G, Croce CM. Targeting microRNAs in cancer: rationale, strategies and challenges. Nat Rev Drug Discov. 2010; 9:775-89. [PubMed: 20885409] 
[5]. Bauman JA, Li SD, Yang A, Huang L, Kole R. Anti-tumor activity of splice-switching oligonucleotides. Nucleic Acids Res. 2010; 38:8348-56. [PubMed: 20719743]

[6]. Zammarchi F, de Stanchina E, Bournazou E, Supakorndej T, Martires K, Riedel E, et al. Antitumorigenic potential of STAT3 alternative splicing modulation. Proc Natl Acad Sci U S A. 2011; 108:17779-84. [PubMed: 22006329]

[7]. Ming X. Cellular delivery of siRNA and antisense oligonucleotides via receptor-mediated endocytosis. Expert Opin Drug Deliv. 2011; 8:435-49. [PubMed: 21381985]

[8]. Juliano R. Nanomedicine: is the wave cresting? Nat Rev Drug Discov. 2013; 12:171-2. [PubMed: 23449291]

[9]. Huang L, Sullenger B, Juliano R. The role of carrier size in the pharmacodynamics of antisense and siRNA oligonucleotides. J Drug Target. 2010; 18:567-74. [PubMed: 20367081]

[10]. Juliano R, Bauman J, Kang H, Ming X. Biological barriers to therapy with antisense and siRNA oligonucleotides. Mol Pharm. 2009; 6:686-95. [PubMed: 19397332]

[11]. Matsumura Y, Maeda H. A new concept for macromolecular therapeutics in cancer chemotherapy: mechanism of tumoritropic accumulation of proteins and the antitumor agent smancs. Cancer Res. 1986; 46:6387-92. [PubMed: 2946403]

[12]. Maeda H, Wu J, Sawa T, Matsumura Y, Hori K. Tumor vascular permeability and the EPR effect in macromolecular therapeutics: a review. J Control Release. 2000; 65:271-84. [PubMed: 10699287]

[13]. Kwon IK, Lee SC, Han B, Park K. Analysis on the current status of targeted drug delivery to tumors. J Control Release. 2012; 164:108-14. [PubMed: 22800574]

[14]. Ruenraroengsak P, Cook JM, Florence AT. Nanosystem drug targeting: Facing up to complex realities. J Control Release. 2010; 141:265-76. [PubMed: 19895862]

[15]. Chauhan VP, Stylianopoulos T, Boucher Y, Jain RK. Delivery of molecular and nanoscale medicine to tumors: transport barriers and strategies. Annu Rev Chem Biomol Eng. 2011; 2:28198. [PubMed: 22432620]

[16]. Heldin CH, Rubin K, Pietras K, Ostman A. High interstitial fluid pressure - an obstacle in cancer therapy. Nat Rev Cancer. 2004; 4:806-13. [PubMed: 15510161]

[17]. Juliano RL, Carver K, Cao C, Ming X. Receptors, endocytosis, and trafficking: the biological basis of targeted delivery of antisense and siRNA oligonucleotides. J Drug Target. 2013; 21:2743. [PubMed: 23163768]

[18]. Muro S. Challenges in design and characterization of ligand-targeted drug delivery systems. J Control Release. 2012; 164:125-37. [PubMed: 22709588]

[19]. Davis ME, Zuckerman JE, Choi CH, Seligson D, Tolcher A, Alabi CA, et al. Evidence of RNAi in humans from systemically administered siRNA via targeted nanoparticles. Nature. 2010; 464:1067-70. [PubMed: 20305636]

[20]. Lv H, Zhang S, Wang B, Cui S, Yan J. Toxicity of cationic lipids and cationic polymers in gene delivery. J Control Release. 2006; 114:100-9. [PubMed: 16831482]

[21]. Juliano RL, Ming X, Nakagawa O, Xu R, Yoo H. Integrin targeted delivery of gene therapeutics. Theranostics. 2011; 1:211-9. [PubMed: 21547161]

[22]. Abes R, Arzumanov AA, Saleh AF, Said Hassane F, Gait MJ, Lebleu B. Splice redirection as a convenient assay to monitor CPP-ON efficiency and mechanism. Methods Mol Biol. 2011; 683:307-20. [PubMed: 21053139]

[23]. Alam MR, Dixit V, Kang H, Li ZB, Chen X, Trejo J, et al. Intracellular delivery of an anionic antisense oligonucleotide via receptor-mediated endocytosis. Nucleic Acids Res. 2008; 36:276476. [PubMed: 18367474]

[24]. Felding-Habermann B, Mueller BM, Romerdahl CA, Cheresh DA. Involvement of integrin alpha V gene expression in human melanoma tumorigenicity. J Clin Invest. 1992; 89:2018-22. [PubMed: 1376331]

[25]. Friedrich J, Seidel C, Ebner R, Kunz-Schughart LA. Spheroid-based drug screen: considerations and practical approach. Nat Protoc. 2009; 4:309-24. [PubMed: 19214182]

[26]. Deneke SM. Thiol-based antioxidants. Curr Top Cell Regul. 2000; 36:151-80. [PubMed: 10842751] 
[27]. Ming X, Carver K, Fisher M, Noel R, Cintrat JC, Gillet D, et al. The small molecule Retro-1 enhances the pharmacological actions of antisense and splice switching oligonucleotides. Nucleic Acids Res. 2013; 41:3673-87. [PubMed: 23396438]

[28]. Ming X, Sato K, Juliano RL. Unconventional internalization mechanisms underlying functional delivery of antisense oligonucleotides via cationic lipoplexes and polyplexes. J Control Release. 2011; 153:83-92. [PubMed: 21571016]

[29]. Ming X, Feng L. Targeted delivery of a splice-switching oligonucleotide by cationic polyplexes of RGD-oligonucleotide conjugate. Mol Pharm. 2012; 9:1502-10. [PubMed: 22497548]

[30]. Dohmen C, Edinger D, Frohlich T, Schreiner L, Lachelt U, Troiber C, et al. Nanosized multifunctional polyplexes for receptor-mediated siRNA delivery. ACS Nano. 2012; 6:5198208. [PubMed: 22646997]

[31]. Juliano RL, Ming X, Nakagawa O. Cellular uptake and intracellular trafficking of antisense and siRNA oligonucleotides. Bioconjug Chem. 2012; 23:147-57. [PubMed: 21992697]

[32]. Montet X, Funovics M, Montet-Abou K, Weissleder R, Josephson L. Multivalent effects of RGD peptides obtained by nanoparticle display. J Med Chem. 2006; 49:6087-93. [PubMed: 17004722]

[33]. Cirak S, Arechavala-Gomeza V, Guglieri M, Feng L, Torelli S, Anthony K, et al. Exon skipping and dystrophin restoration in patients with Duchenne muscular dystrophy after systemic phosphorodiamidate morpholino oligomer treatment: an open-label, phase 2, dose-escalation study. Lancet. 2011; 378:595-605. [PubMed: 21784508]

[34]. Sazani P, Kang SH, Maier MA, Wei C, Dillman J, Summerton J, et al. Nuclear antisense effects of neutral, anionic and cationic oligonucleotide analogs. Nucleic Acids Res. 2001; 29:3965-74. [PubMed: 11574678]

[35]. Minchinton AI, Tannock IF. Drug penetration in solid tumours. Nat Rev Cancer. 2006; 6:583-92. [PubMed: 16862189]

[36]. Mehta G, Hsiao AY, Ingram M, Luker GD, Takayama S. Opportunities and challenges for use of tumor spheroids as models to test drug delivery and efficacy. J Control Release. 2012; 164:192204. [PubMed: 22613880]

[37]. Huang K, Ma H, Liu J, Huo S, Kumar A, Wei T, et al. Size-dependent localization and penetration of ultrasmall gold nanoparticles in cancer cells, multicellular spheroids, and tumors in vivo. ACS Nano. 2012; 6:4483-93. [PubMed: 22540892]

[38]. Goodman TT, Olive PL, Pun SH. Increased nanoparticle penetration in collagenase-treated multicellular spheroids. Int J Nanomedicine. 2007; 2:265-74. [PubMed: 17722554]

[39]. Kratz F. Albumin as a drug carrier: design of prodrugs, drug conjugates and nanoparticles. J Control Release. 2008; 132:171-83. [PubMed: 18582981] 

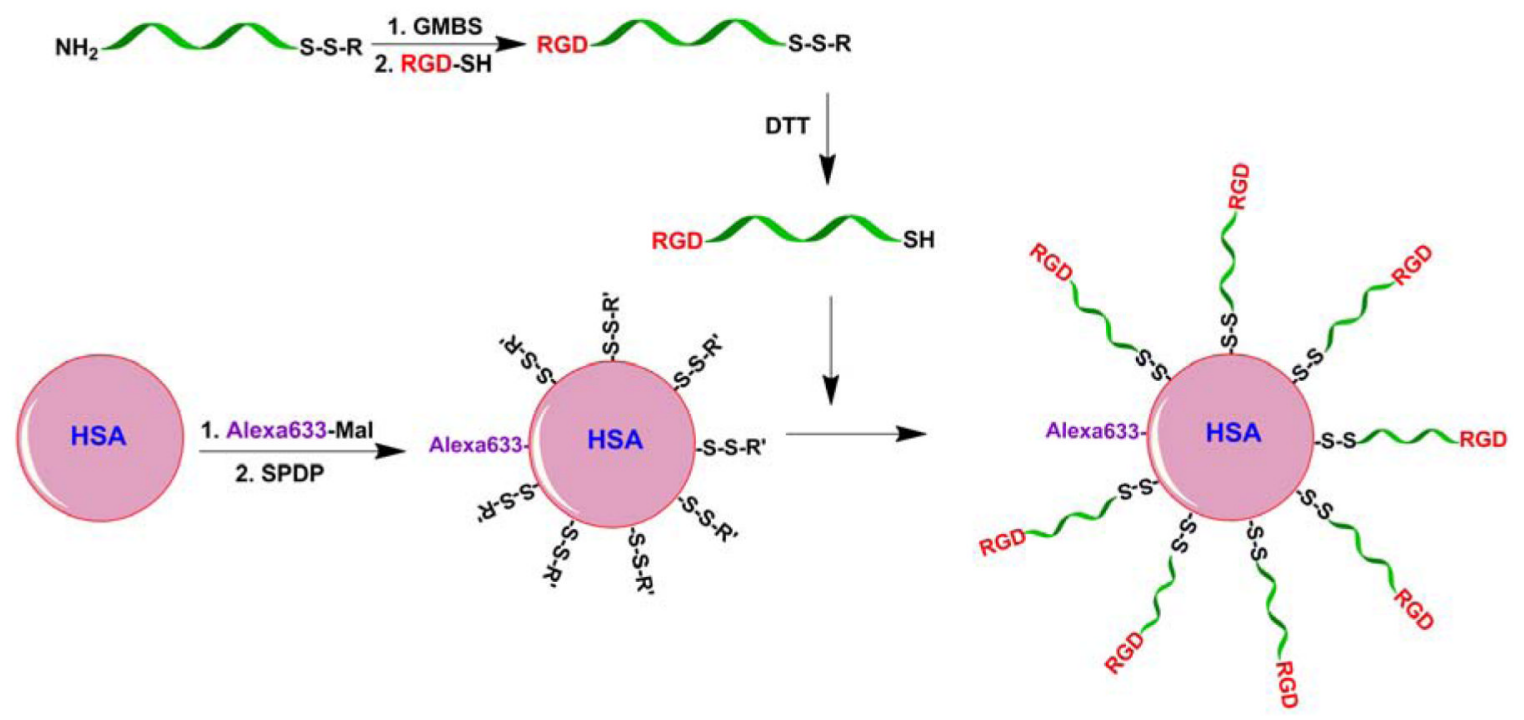

Fig 1.

Preparation of HSA-(PMO-RGD) 15 nanoconjugates ${ }^{a}$

a. Alexa 633-Mal = Alexa Fluor 633 C5 maleimde; RGD-SH = cyclo[RGDfK-COCH $\left.{ }_{2} \mathrm{SH}\right]$; 
A

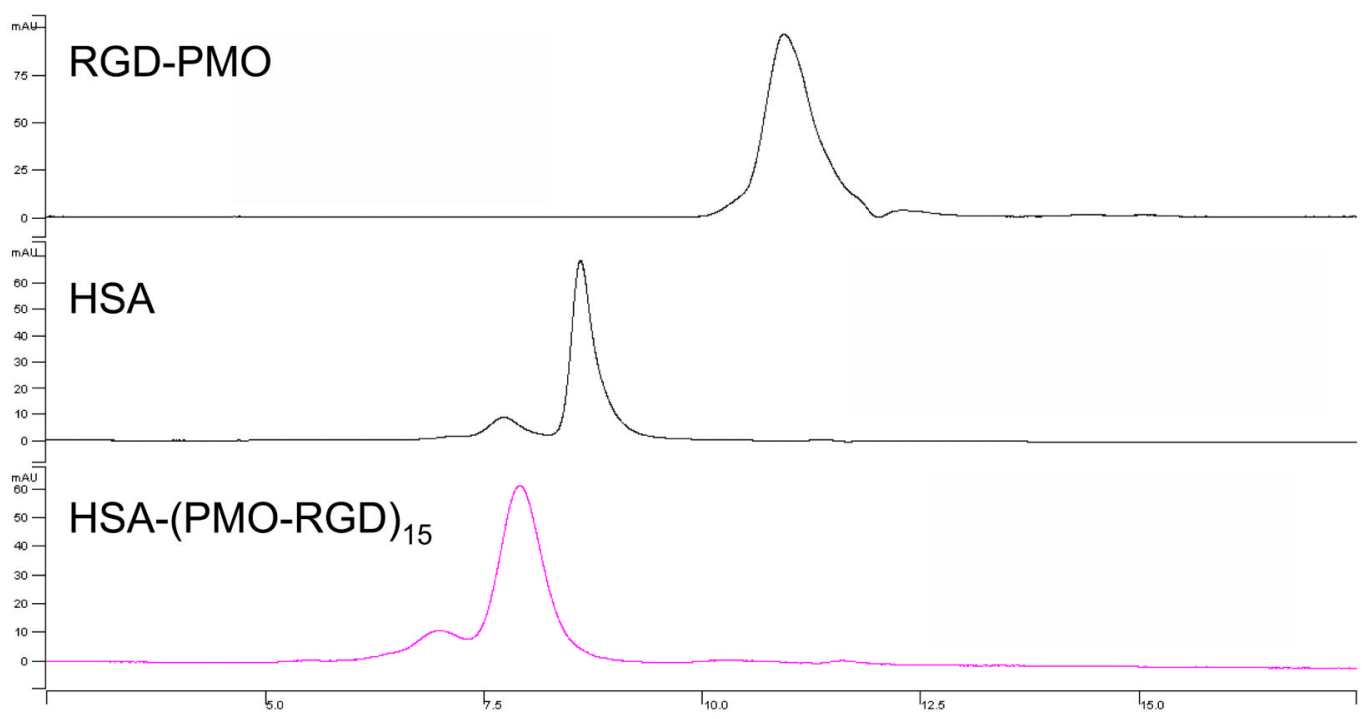

B

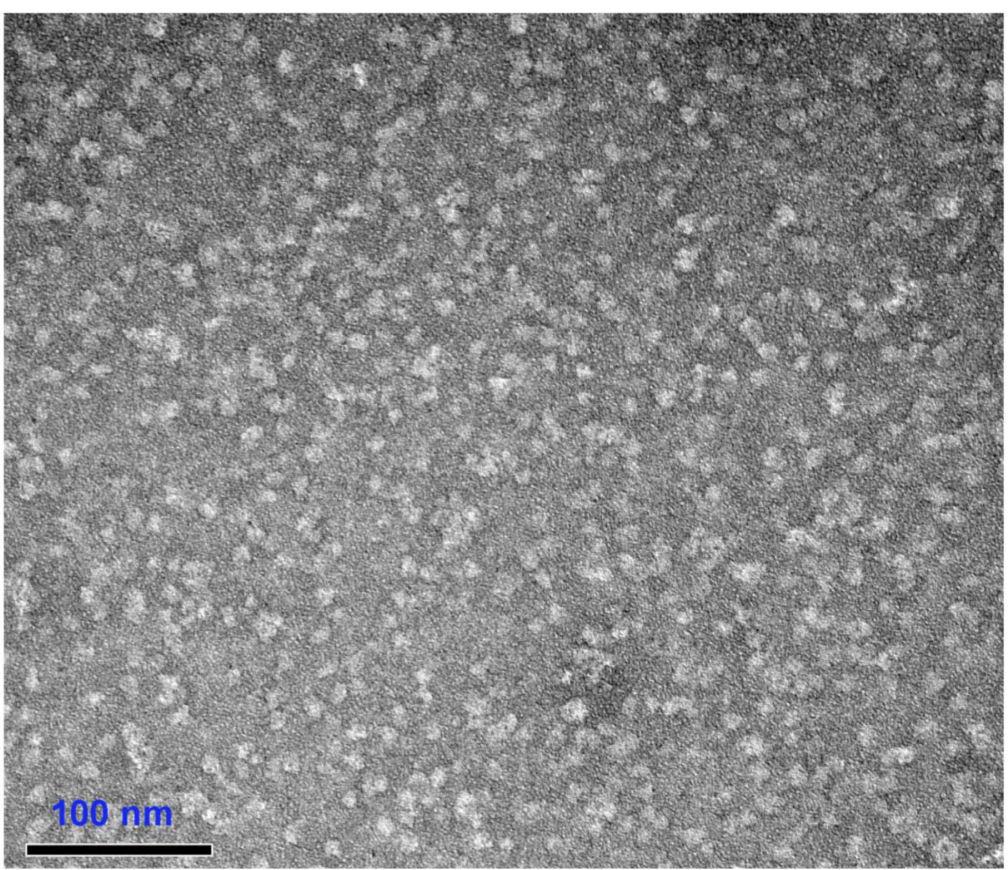

Fig 2.

Characterization of Nanoconjugates. A. SEC-HPLC chromatography of RGD-PMO conjugates, HSA, and HSA-(PMO-RGD) 15 nanoconjugates. B. TEM image of HSA-(PMORGD) ${ }_{15}$ nanoconjugates. The sample is counterstained by uranyl acetate. The average particle size is estimated to be $10 \mathrm{~nm}$. 

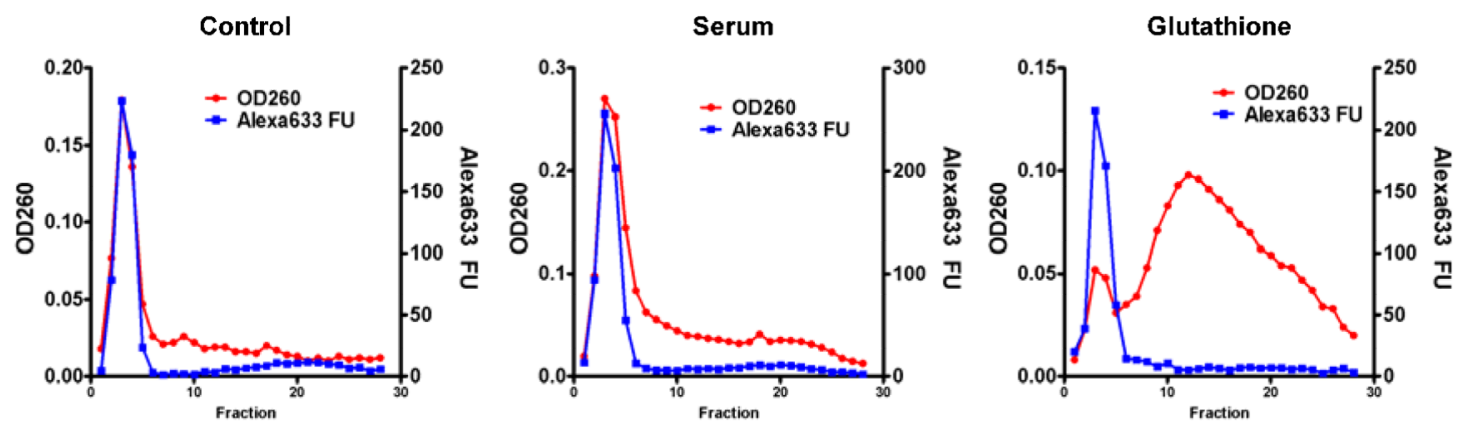

Fig 3.

Serum stability and release of PMO by sulfhydryls. The HSA-(PMO-RGD) 15 nanoconjugates containing $1 \mu \mathrm{M}$ PMO were incubated in PBS containing 20\% serum at 37 ${ }^{\circ} \mathrm{C}$ for $16 \mathrm{~h}$ or in PBS containing $10 \mathrm{mM}$ glutathione and $100 \mu \mathrm{M}$ cysteine at at $37^{\circ} \mathrm{C}$ for $4 \mathrm{~h}$, using PBS as a control. After incubation, samples were eluted in a column with Sephadex G-100 gel. The PMO contents in the fractions were then detected by OD260, while the albumin was detected by Alexa Fluor 633 fluorescence. 


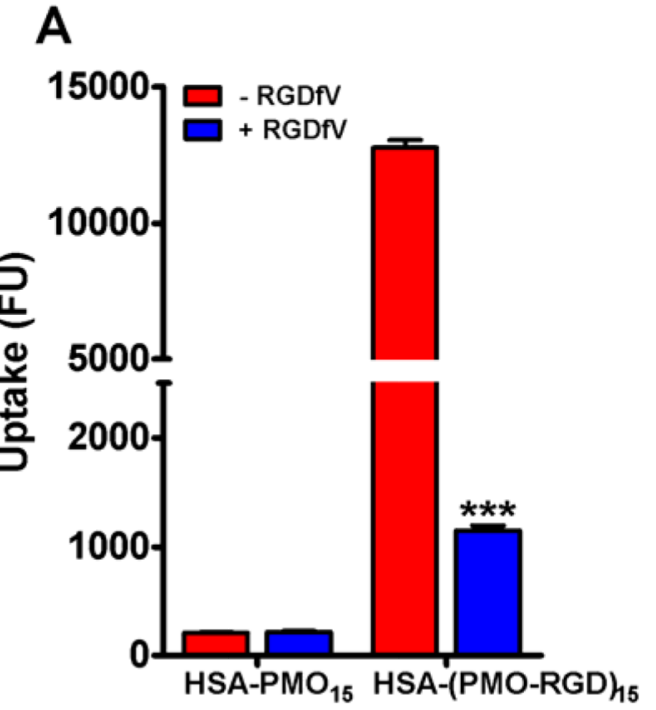

\section{C}

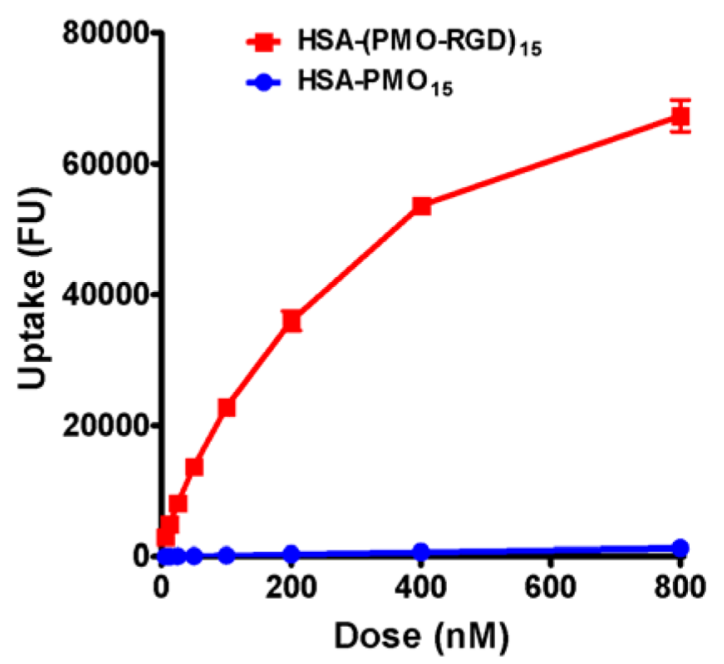

B

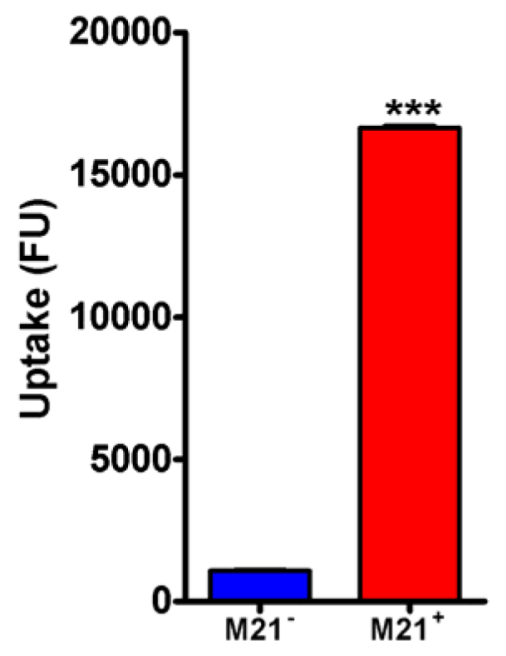

D

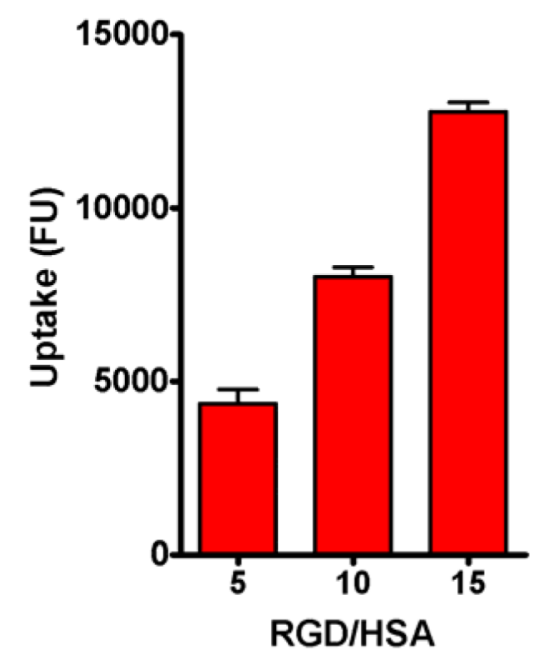

Fig 4.

Cellular uptake of nanoconjugates. A. A375/Luc705 cells were treated with HSA-PMO 15 and HSA-(PMO-RGD) ${ }_{15}$ (both contain $50 \mathrm{nM}$ PMO) in the absence or presence of excess free RGD peptide (RGDfV, $10 \mu \mathrm{M}$ ) for 4 hours and total cellular uptake of the Alexa 633labeled nanoconjugates was measured by flow cytometry. B. Uptake of HSA-(PMO-RGD) 15 (50 nM PMO) was compared in $\alpha v \beta 3$ positive $\mathrm{M}^{2} 1^{+}$cells and M21- cells that do not express this integrin. C. A375/Luc705 cells were treated with increasing concentrations of HSA-PMO 15 and HSA-(PMO-RGD) 15 for 4 hours followed by measurement of total cellular uptake by flow cytometry. D. Uptake of the RGD targeted nanoconjugates of different ratios of RGD-PMO to albumin (5, 10, and 15) and containing $3.3 \mathrm{nM}$ HSA was compared in A375/Luc705 cells. Data represent mean \pm S.D. of a representative experiment in triplicate. Statistical significance was evaluated using $t$-test for two-sample comparison or ANOVA followed by Dunnet's test for multiple comparisons. *** indicates $p<0.001$. 


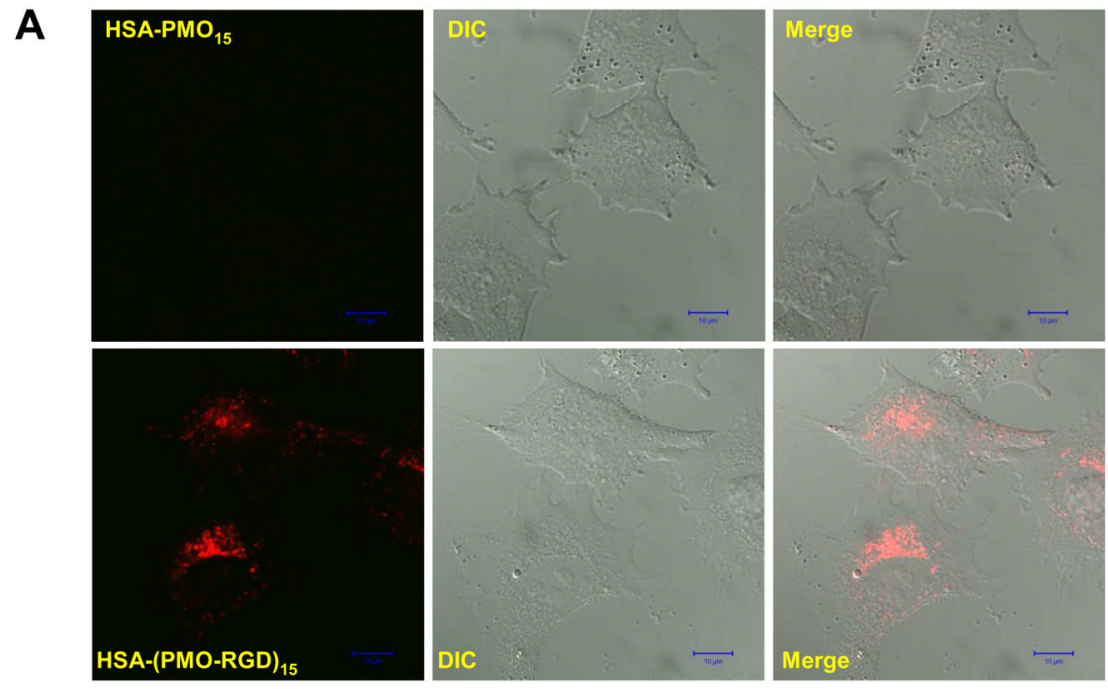

B
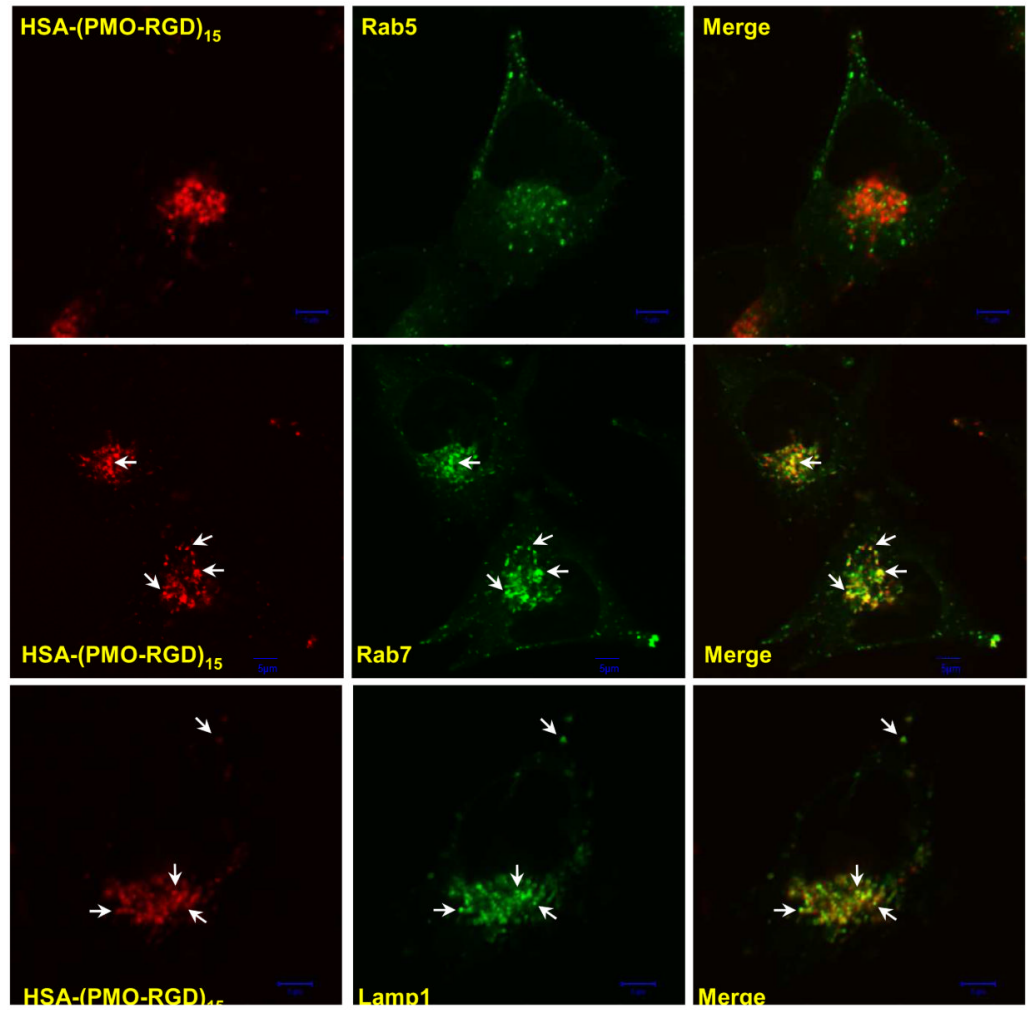

Fig 5.

Subcellular localization of the nanoconjugates. A. A375/Luc705 cells were treated with with HSA-PMO 15 and HSA-(PMO-RGD) ${ }_{15}$ for $4 \mathrm{~h}$, and then were observed by confocal microscopy. B. A375/Luc705 cells were transfected with GFP chimeras that serve as markers for several endomembrane compartments ( $\operatorname{Rab} 5$, early endosomes; Rab 7, late endosomes; Lamp1, lysosome). Thereafter, cells were incubated with $50 \mathrm{nM}$ Alexa 633 labeled targeted nanoconjugates for $4 \mathrm{~h}$. Live cells were observed by confocal microscopy. Green image, GFP fluorescence. Red image, Alexa 633 fluorescence. 
A
B
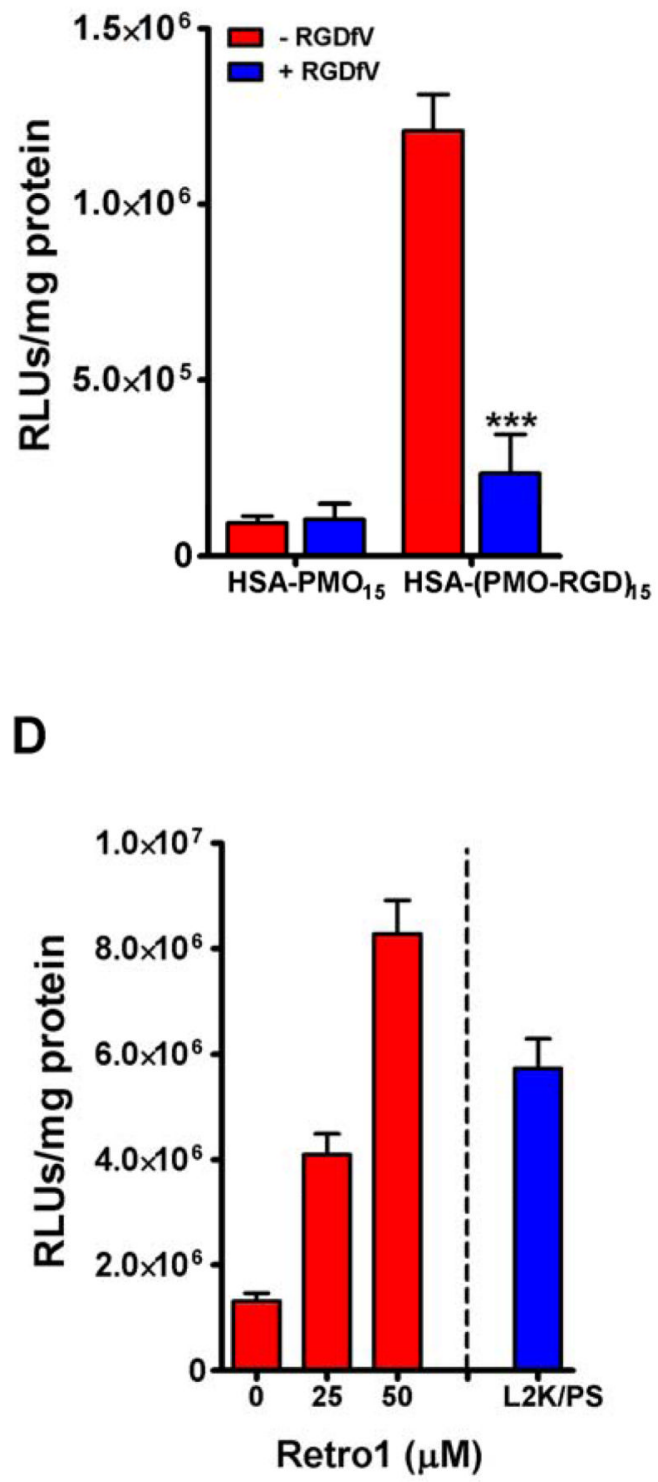

Fig 6.

Functional delivery of SSOs by the nanoconjugates. A. Comparison of luciferase induction by the treatments of PMO, RGD-PMO, HSA-PMO ${ }_{15}$, and HSA-(PMO-RGD) ${ }_{15}$ (all contain $50 \mathrm{nM}$ PMO). B. The luciferase induction by HSA-PMO 15 and HSA-(PMO-RGD) 15 (both contain $50 \mathrm{nM}$ PMO) in the absence or presence of excess free RGD peptide. C. In the dosedependence experiment, A375/Luc705 cells were treated with increasing concentrations of the HSA-PMO 15 and HSA-(PMO-RGD) 15 for $16 \mathrm{~h}$ followed by another 48-h culture. D. Retro-1 enhances functional delivery by the targeted nanoconjugates. After treatment with the targeted nanoconjugates, A375/Luc705 cells were treated by various amounts of Retro-1. The luciferase activity was measured after 24 -h culture. The blue bar represents the luciferase induction by Lipofectamine 2000 complexes of negatively charged PS oligonucleotide in the same sequence and at the same concentration. 


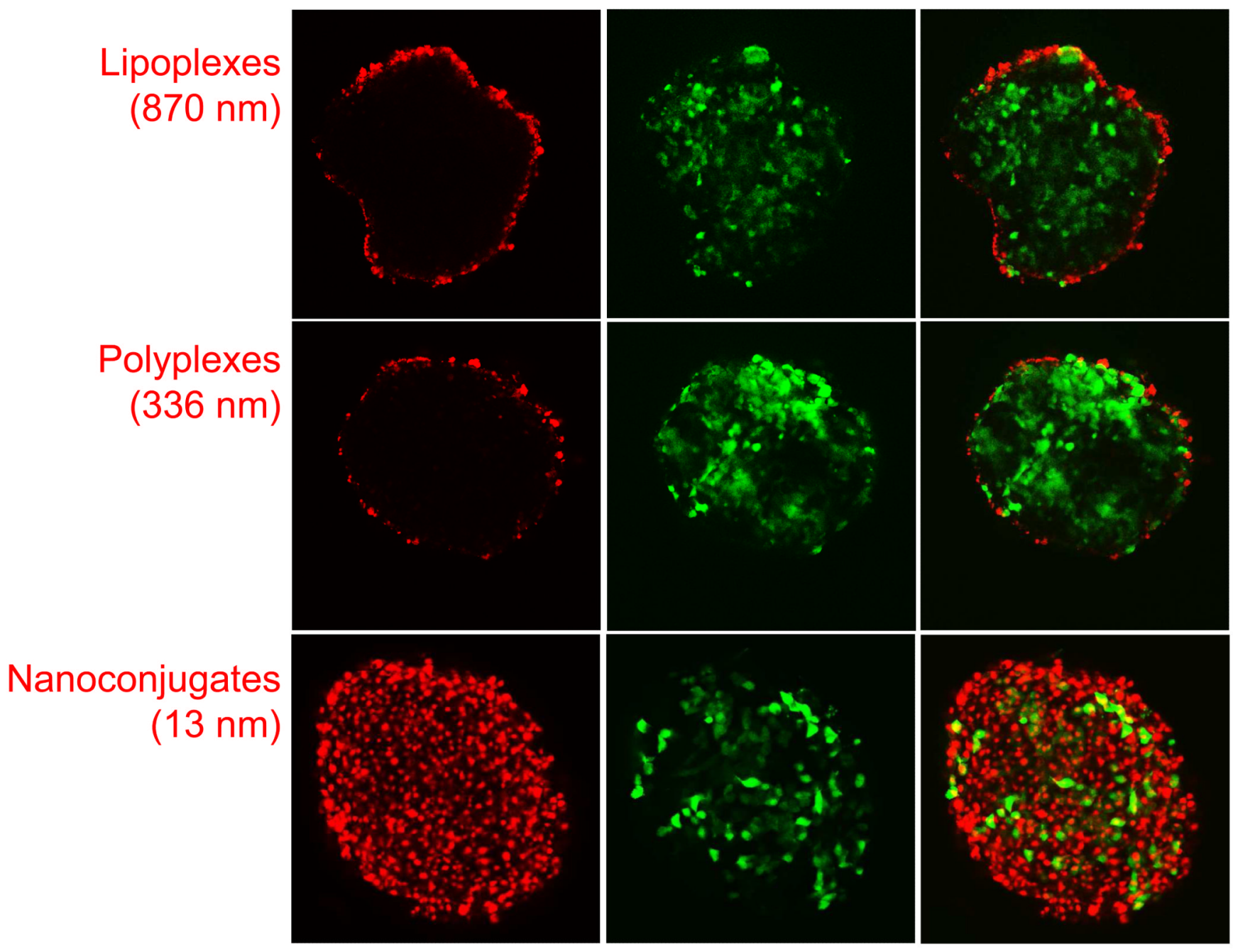

Fig 7.

Penetration of the nanoconjugates in tumor spheroids. Tumor spheroids of A375/GFP cells were treated with the RGD targeted nanoconjugates, the lipoplexes and polyplexes of PS SSO (all contain $100 \mathrm{nM} \mathrm{SSOs)} \mathrm{for} 4 \mathrm{~h}$. After fixation, the spheroids were observed by confocal microscopy. Green image: GFP fluorescence. Red image: Alexa 633 fluorescence for the nanoconjugates or TAMRA fluorescence for the other nanoparticles. 


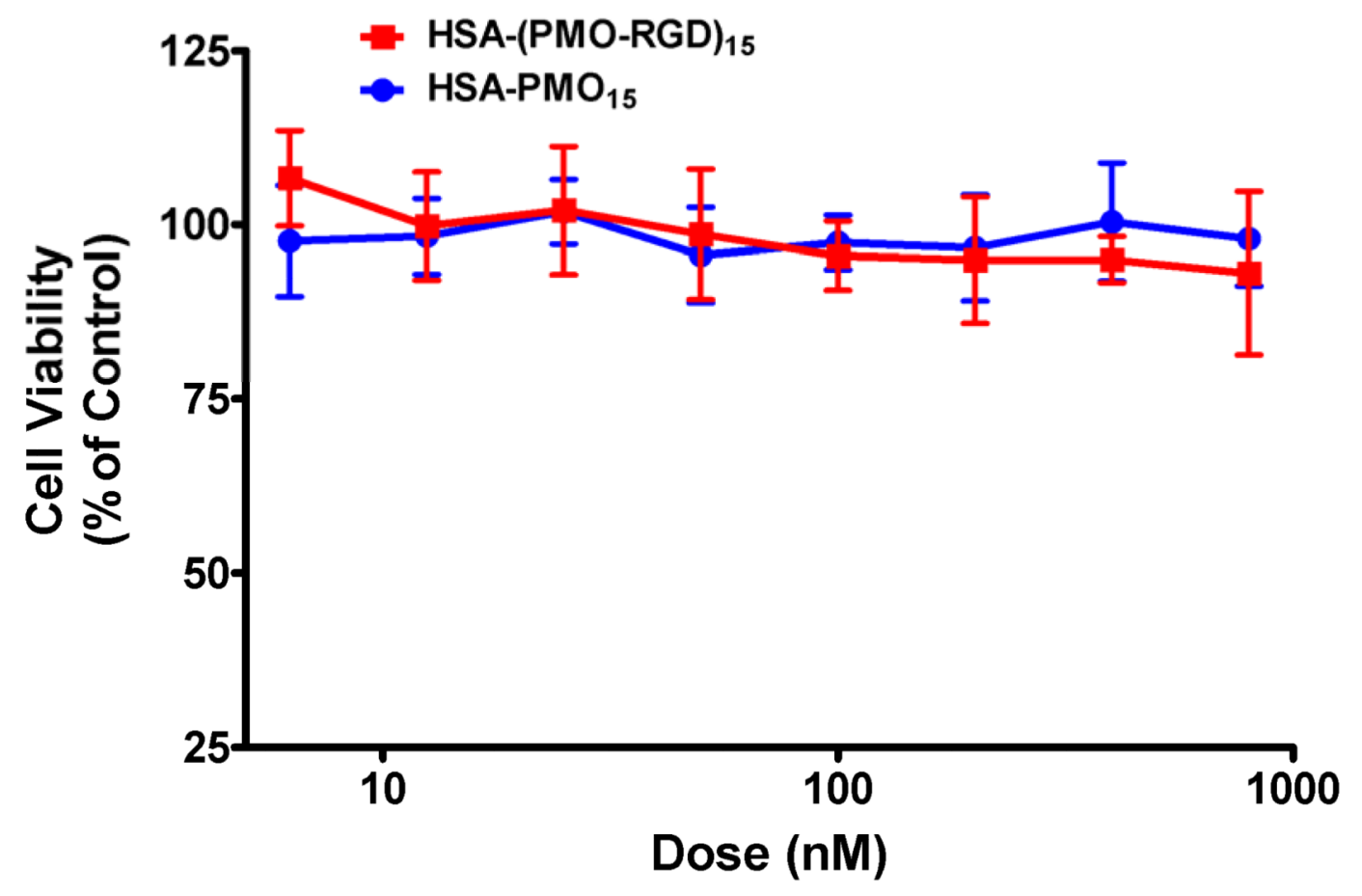

Fig 8.

Cytotoxicity of the Nanoconjugates. The cytotoxicity of the HSA-PMO 15 and HSA-(PMORGD) 15 nanoconjugates to A375/Luc705 cells was measured in 96-well plates with the Alamar Blue assay. 


\section{Table 1}

Particle sizes of the nanoconjugates ${ }^{a}$

\begin{tabular}{ccc}
\hline & Particle Size (nm) & P.I. \\
\hline HSA & $7.14 \pm 0.03$ & $0.34 \pm 0.01$ \\
HSA-PMO & $12.74 \pm 0.52$ & $0.37 \pm 0.03$ \\
HSA-PMO-RGD & $12.95 \pm 0.14$ & $0.31 \pm 0.03$ \\
\hline
\end{tabular}

${ }^{a}$ Results are expressed as mean $\pm \mathrm{SD}(\mathrm{n}=3)$ 